\title{
CYPELLA HAUTHALII (KUNTZE) FOSTER SUBSP. OPALINA RAVENNA NUEVA CITA PARA EL PARAGUAY ${ }^{1}$
}

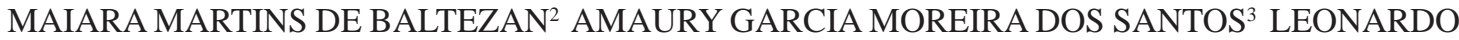 \\ PAZ DEBLE ${ }^{4}$
}

\section{RESUMEN}

Cypella hauthalii subsp. opalina es citada por la primera vez a flora indígena del Paraguay. Informaciones sobre su ocurrencia en el país y las principales diferencias con C. hauthalii subsp. hauthalii son comentados.

Palabras-clave: Cypella; Distribución geográfica; Itapuá; Tigridieae.

\author{
ABSTRACT \\ [Cypella hauthalii (Kuntze) Foster subsp. opalina Ravenna a new record from Paraguay] \\ Cypella hauthalii subsp. opalina is added for the Paraguayan Flora, and are supplied information about its \\ occurrence in the country and commented points of morphologic differences with $C$. hauthalii subsp. \\ hauthalii \\ Key words: Cypella; Geographic distribution; Itapuá; Tigridieae.
}

\section{INTRODUCCIÓN}

Cypella es un género perteneciente a la familia Iridaceae, con distribución geográfica en el centro-sureste de América del Sur, con 38 especies aceptadas en el World Checklist of Iridaceae (WCI) (Barker, 2019). El género incluye plantas bulbosas pequeñas o medianas, con hojas plegadas, y espatas contiendo dos valvas convolutas, siendo la externa más corta que la interna, la inflorescencia es reducida y contiene por espata una o dos flores que pueden ser amarillas, doradas, anaranjadas, blancas o raramente lilas (Ravenna, 2003). Los tépalos se disponen en dos ciclos, los internos menores con lámina de estructura compleja, tridimensional, con la base en forma de uña, ascendente o no, los externos son oblongos y generalmente pandurados, con base teniendo uña más ancha, formando con la uña de los tépalos internos una

${ }^{1}$ Recebido em 04-10-2018 e aceito para publicação em 06-03-2019

${ }^{2}$ Universidade Federal do Pampa, campus Dom Pedrito, rua 21 de abril 80, CEP 96450-000. maiarabaltezan17@gmail.com

${ }^{3}$ Universidade Federal de Pelotas, PPG em Zootecnia, Pelotas, Campus Universitário, s.n., CEP 96160-900. amaury_dp@hotmail.com

${ }^{4}$ Núcleo de Pesquisas Botânicas Balduíno Rambo, Universidade Federal de Santa Maria, Av. Roraima, CEP 97105-900.deble.biol@gmail.com concavidad central (Deble et al., 2015a; b; Deble \& Alves, 2017; Deble, 2017).

De los primeros estudios de Cypella para el Paraguay, se destaca la investigación de Baker (1903) que presento lista y descripción de los géneros y especies de Iridaceae coleccionadas en el Paraguay por el médico y naturalista suizo Émile Hassler (1864-1937). Baker reconoce 24 especies de Iridaceae para el país, distribuidas en cinco géneros, siendo que para Cypella fueran tratados cinco taxones: Cypella coriifolia Baker, C. gracilis (Klatt) Baker, C. gracilis $\mathrm{f}$. humilis Baker, $C$. plumbea Lindley y $C$. herbertii (Herbert) Herbert. Más tarde, Ravenna (1981) describió Cypella armosa Ravenna y $C$. curuzupensis Ravenna como indígenas del Paraguay. Subsiguientemente, Ravenna (2000) citó la ocurrencia de C. laxa para a flora del referido país, y en una última contribución, Ravenna (2003) presentó el estudio de las Iridaceae del Paraguay, reconociendo seis especies para Cypella: C. amambaica Ravenna, C. armosa Ravenna, C. curuzupensis Ravenna, C. hauthalii (Kuntze) Foster subsp. hauthalii, C. laxa Ravenna y C. lilacea Ravenna.

Cypella hauthalii fue descripta por Kuntze (1898) y ubicada en el género Alophia Herbert. Después, Schumann (1900) transfirió esta especie para Herbertia Sweet. Más tarde, Foster 
(1950) al analizar el tipo de A. hauthalii, evidenció que el taxón estaba mal ubicado en el género Alophia, y teniendo como base las ramas del estilo, que presentan longas crestas, el autor concluyo que esta especie debería ser transferida para Cypella, proponiendo la nueva combinación Cypella hauthalii (Kuntze) Foster. Posterior al trabajo de Foster, Goldblatt (1975) trató el taxón en Trifurcia Herbert y más tarde en Herbertia (Goldblatt, 1978). Ravenna (1981) restableció nuevamente el nombre Cypella hauthalii como válido, y reconoció una nueva subespecie para el taxón: C. hauthalii subsp. opalina.

Más recientemente, Chauveau et al. (2014) propusieran $C$. hauthalii subsp. minuticristata Chauveau \& L. Eggers y $C$. hauthalii pasó a tener tres subespecies (hauthalii, minuticristata y opalina). Según Ravenna (2003) y Chauveau et al. (2014) las subespecies presentan distribución geográfica distinta, teniendo en cuenta que $C$. hauthalii subsp. hauthalii se distribuye más en la porción occidental, en el sur del Paraguay y suroeste de Misiones y norte de Corrientes en la Argentina. La subespecie opalina, ocurre en el sur de Misiones y nordeste de Corrientes, además en el oeste del Rio Grande del Sur, en Brasil, mientras la subespecie minuticristata tiene la distribución más oriental, donde es endémica en el centro del Rio Grande del Sur.

Durante visita técnica a una propiedad privada en la localidad de Caraguatá, en el Departamento de Itapuá, sur del Paraguay $\left(27^{\circ} 14^{\prime} 35.9^{\prime \prime} \mathrm{S} 56^{\circ} 04^{\prime} 47.2^{\prime \prime} \mathrm{W}\right)$, cerca del río Paraná, fueron encontrados individuos de una Cypella en ambiente campestre con pastizales bajos, utilizados para pastoreo de bovinos. Los especímenes fueron fotografiados y posteriormente identificados como $C$. hauthalii subsp. opalina. Durante la revisión de herbarios también encontramos una colección de Hassler, para el mismo departamento. Así es necesario la publicación de este trabajo para actualizar las informaciones sobre la distribución geográfica de Cypella hauthalii subsp. opalina que hasta ahora no es reconocida para la flora del Paraguay.

\section{RESULTADOS}

Cypella hauthalii (Kuntze) Foster subsp. opalina Ravenna, Wrightia 7(1): 21. 1981. TIPO: ARGENTINA, Corrientes, Santo Tomé, Garruchos: "Culta in Santiago ex bulbo ad ripas fluminis Uruguay pr. Garruchos prov. Corrientes Argentinae collecto" X-1980, P.F. Ravenna 3300 (Herb. Rav.).

Descripción: Planta de 6-20 cm, tallo subterráneo de $4 \mathrm{~cm}$. Bulbo globoso u ovoide, $10-18 \times 9-15 \mathrm{~mm}$, prolongado en un collar, de hasta $15 \mathrm{~mm}$ de comprimento; catafilos marrón oscuro, anchamente ovado, agudo. Hojas basales en la antesis: 2-5; lámina linear-eliptica 5-14 × $0.2-0.6 \mathrm{~cm}$. Hoja caulinar más basal linearensiforme, 4-12 cm de longitud, base envolviendo el tallo; lámina 3-6 (9) × 0.2-0.6 $\mathrm{cm}$. Ramos floríferos 4-15 cm, con 1-2 ramificaciones. Espatas 1-5 por ramificación, 2.4-4.8 × 0.4-0.5 cm, herbáceas, verdes, 2valvadas, 2-flora, pedunculadas, pedúnculos $0.6-2.8 \mathrm{~cm}$; valva externa $15-29 \mathrm{~mm}$, valva interna $24-41 \mathrm{~mm}$, y terminando en una parte hialina con líneas paralelas marrón-oscuro; pedicelo filiforme, más corto que la espata, 20$35 \mathrm{~mm}$. Flores 33-50 mm diámetro, blancas, o blanco-crema con puntitos purpuro; concavidad central $14-18 \mathrm{~mm}$ diámetro y $24-33 \mathrm{~mm}$ de profundidad. Tépalos externos, espatulados u obovados , 26-35 mm, erecto por $1 / 2$ de su largo, después patente y revolutos en el ápice; lámina blanca, manchado de blanco-crema y se tornando blanco-azulada en el fin de la antesis, con una pequeña mancha amarilla y líneas marrón-rojizas en la base, 14-23 × 17-28 mm, erectas en la mitad proximal, después levemente revoluta, ápice truncado o redondeado, apiculada; unguículo cuneado, 13-15 mm longitud, 4-5 $\mathrm{mm}$ ancho en la base y $8-10 \mathrm{~mm}$ ancho en el ápice, amarillo-pálido, con líneas purpuro-rojizas, tricomas glandulares abundantes. Tépalos internos arcuado-recurvados, 14$17 \mathrm{~mm}$ longitud, la mitad proximal ascendente, 


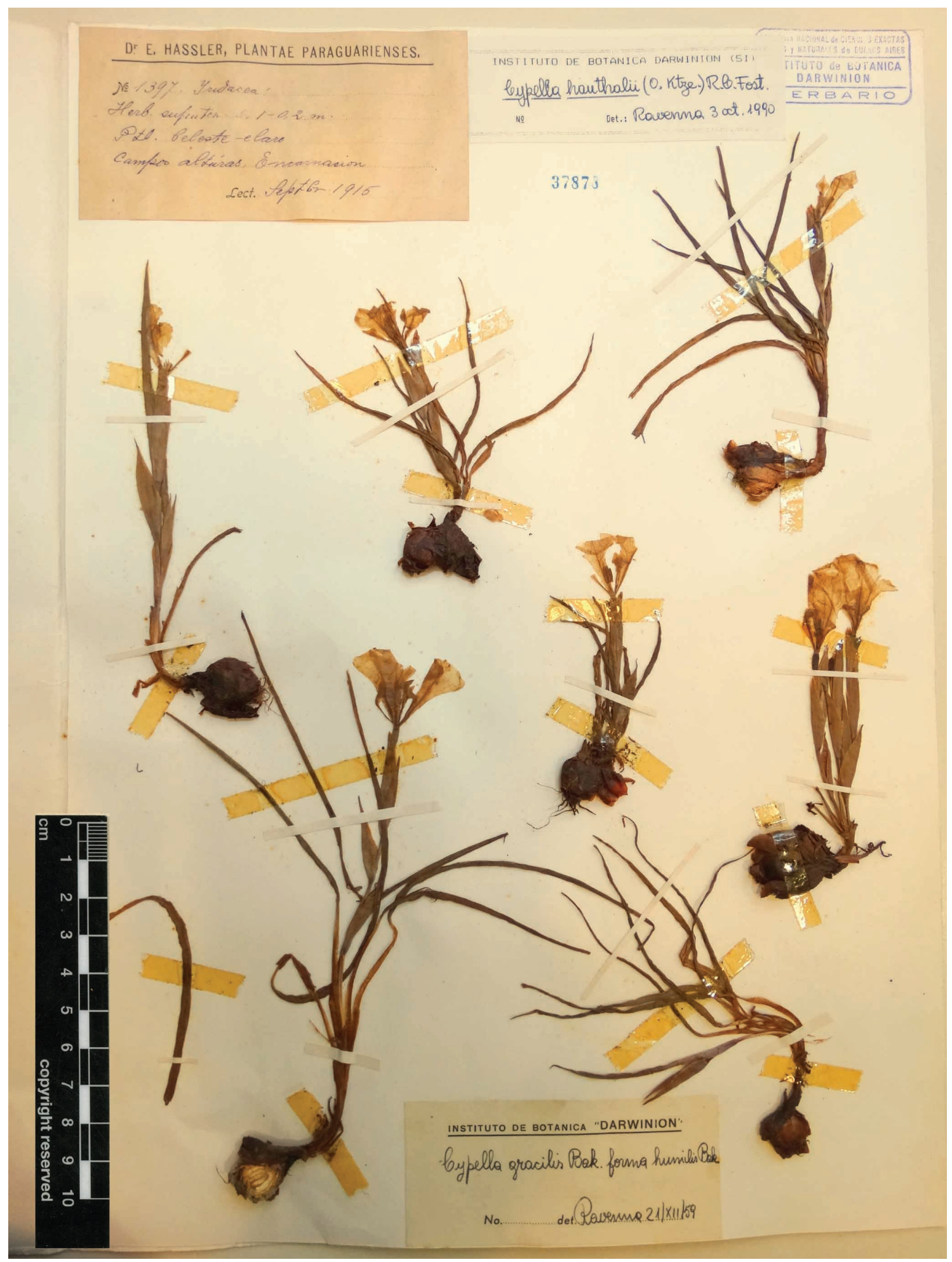

FIGURA 1 - Cypella hauthalii (Kuntze) Foster subsp. opalina Ravenna (de E. Hassler 1397). 
declinados, después curvados arriba, el tercio distal incurvado y reclinado; laminas 4-6 mm ancho, romboide, apiculada en el ápice, blanca, con una porción central de forma casi circular y densamente con tricomas lipídicos, envueltos por una porción lateral más alta, amarilla y con manchas purpuro; unguículo casi linear, 9-10 mm longitud, 1.5-2.1 mm ancho en la base y 3.6-4.1 mm ancho en el ápice, amarillo-pálido, con líneas purpuro-rojizas, tricomas glandulares abundantes. Estambres con filamentos filiformes 5-6.5 mm longitud, levemente declinados, translucidos, y blanquecinos en el ápice, purpuro y dilatado en la base; anteras oblongas 4.6-6 × 1.2-1.6 mm; conectivo blanquecino, $1-$ $1.2 \mathrm{~mm}$, lóculos grises, polen ocráceo u ocráceoamarillento. Ovario verde-pálido, 5-6× 1.8-2.1 $\mathrm{mm}$. Estilo 13-17 mm longitud. Ramos del estilo surcados, declinados, 2.5-4 mm longitud, crestas en el ápice 3, translucidas y blanquecinas o azuladas; crestas adaxiales lanceoladas, 2.5$5 \mathrm{~mm}$ longitud, cresta abaxial obsoleta o deltada, 0.2-2.5 mm longitud, ápice agudo. Capsula obovada, $8-10 \mathrm{~mm} \times 4-5 \mathrm{~mm}$, con puntitos y líneas glandulares. Semillas oblongas u obcónicas, 2-2.5 mm, anguladas, marrón, epidermis faveolada.

Etimología: El epíteto “opalina” es debido el color del perigonio que es blanco-opalino.

Distribución y hábitat: Cypella hauthalii subsp. opalina ocurre en el noroeste del Río Grande del Sur (Brasil), sur de Misiones, nordeste de Corrientes (Argentina) y en el extremo sur del Paraguay, donde se encontró en el departamento de Itapuá. Las poblaciones están compuestas por muchos individuos que crecen en pastizales nativos, preferentemente en lugares poco profundos, pedregosos y rocosos, pero también en suelos lateríticos profundos desarrollados a partir de rocas volcánicas. $C$. hauthalii subsp. opalina es más frecuente entre Garruchos, Santo Tomé (Argentina) y Santiago (Brasil), donde ocurre en una banda más o menos continua con ca. de $60 \mathrm{~km}$ de ancho. $C$. hauthalii subsp. opalina es el taxón más común de Iridaceae bulbosa a lo largo de esta área de ocurrencia, pero esta especie se vuelve rara fuera de esta región.

Observaciones: Los especímenes con flores y cápsulas se pueden encontrar entre septiembre y diciembre. Las flores se abren solo en un día a media mañana y se marchitan a media tarde. En días nublados, las flores permanecen abiertas hasta la tarde. En años favorables, los especímenes florecen en plenitud y sus flores blanco-opalinas aseguran una hermosa vista en los pastizales que ocurren.

Material examinado: PARAGUAY. Itapuá. Encarnación, “campos altura Encarnación”, XI1915, E. Hassler 1397 (SI!) (Figura 1).

\section{CONCLUSIÓN}

Con los nuevos registros se comprueba la presencia de Cypella hauthalii subsp. opalina en el Paraguay, donde ocurre en el departamento de Itapuá, en el sur del país. Dita subespecie es muy fácil de ser separada de los demás táxones de Cypella que ocurren en el país, por ser el único con flores blancas y por la depresión central muy profunda. Cypella hauthalli subsp. opalina es muy cerca de la subsp. minuticristata que ocurre en el centro del Rio Grande del Sur (Brasil), de la cual separase únicamente por el estilo con crestas adaxiales más largas $(2,5-5$ $\mathrm{mm}$ vs. $0.1-1.5 \mathrm{~mm}$ ).

\section{REFERENCIAS}

BAKER, J. G. Iridaceae Plantae Hassleriana. Bulletin de l'Herbier Boissier ser. 2, 3, p. 1102-1106, 1903.

BARKER, C. World Checklist of Iridaceae. Facilitated by the Royal Botanic Gardens, Kew. Acceso en: http://apps.kew.org/wcsp/ (accessed 4 April 2019).

CHAUVEAU, O., PASTORI, T, SOUZA-CHIES, T. T., EGGERS, L. Overlooked diversity in Brazilian Cypella (Iridaceae, Iridoideae): four new taxa from the Río de la Plata grasslands. Phytotaxa 174, n. 1, p. 25-42, 2014. http:// dx.doi.org/10.11646/phytotaxa.174.1.2

DEBLE, L. P., ALVES, F. da S., GONZÁLEZ, A., de OLIVEIRA, A.S. Three new species of Cypella (Iridaceae) from South America, and 
taxonomic delimitation of $C$. suffusa Ravenna. Phytotaxa 236, n. 2, p. 101-120, 2015a. http:// dx.doi.org/10.11646/phytotaxa.236.2.1

DEBLE, L. P., ALVES, F. da S., de OLIVEIRA, A.S. Three new species of the genus Cypella (Iridaceae, Tigridieae). Darwiniana, nueva série 3, n. 2, p. 235-253, 2015b. http:// dx.doi.org10.14522/darwiniana.2015.31.666

DEBLE, L.P. La identificación de Cypella exilis Ravenna (Iridaceae). Balduinia 56, p. 27-34, 2017.

DEBLE, L.P.; ALVES F. S. da. Taxonomic novelties for the genus Cypella (Iridaceae): new species, synonymies and nomenclatural types. Kew Bulletin, Kew 72, n. 41, p. 1-18, 2017.

FOSTER, R.C. Studies in the Iridaceae VI, Miscelaneous novelties and transfers. Contributions from the Gray Herbarium of Harvard University 171, p. 22-28. 1950.

GOLDBLATT, P. Revision of the bulbous Iridaceae of North America. Brittonia 27, p. 373-385, 1975.

GOLDBLATT, P. Herbertia (Iridaceae) reinstated as a valid generic name. Annals of the Missouri Botanic Garden 64, p. 378-379, 1978.

KUNTZE, O. Iridaceae. Revisio Generum Plantarum 3, p. 304-309, 1998 http://dx.doi.org/10.5962/ bhl.title. 327

RAVENNA, P. F. Eight new species and two new subspecies of Cypella (Iridaceae). Wrightia 7, n. 1, p. 13-21, 1981.

RAVENNA, P. F. Cypella laxa (Iridaceae) reported in the flora of Paraguay. Onira Botanical Leaflets 4, p. 1-2, 2000.

RAVENNA, P. F. Flora de Paraguay. Iridaceae. Botanica Australis 4: 1-60, 2003.

SCHUMANN, K. VI. Neue Arten der Siphonogamen 1898. Just's botanischer jahresbericht Systematisch geordnetes repertorium der botanischen liter 26, n.1, p. 323-396, 1900. 